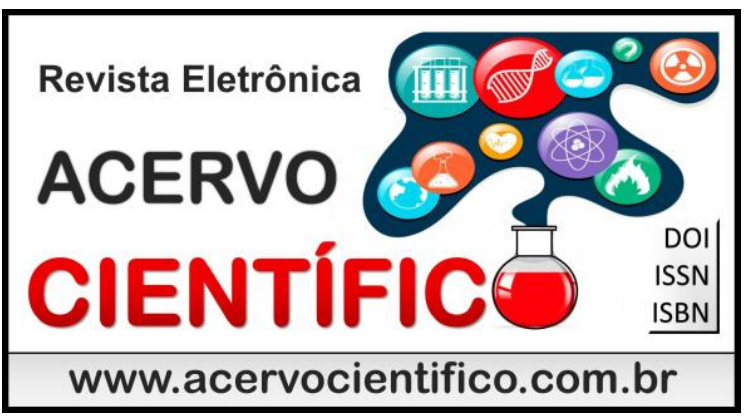

ARTIGO DE REVISÃo

Recebido em: 10/2018

Aceito em: 11/2018

Publicado em: 1/2019

\title{
As relações entre formação humana e a globalização: Uma análise de educação e trabalho
}

He relations between human training and globalization: An analysis of education and work

Las relaciones entre formación humana y la globalización: Un análisis de educación y trabajo

\section{Mauro Lúcio Batista Cazarotti ${ }^{1}$}

Resumo: O presente estudo tem como objetivo a análise das relações entre formação humana, educação e trabalho e compreender como formador de desenvolvimento humano ao longo do tempo, destacamdo-se fundamentos, controvérsias e desafios. Dentre os autores pesquisados para a constituição conceitual do trabalho, destacaram-se Ramos (2002), Saviani (2007), Felizardo (2010) e Santagada (2007). Utiliza-se como metodologia à pesquisa descritiva, tendo como coleta de dados o levantamento bibliográfico. Concluise que é relevante a compreensão de como ocorre o processo formador de desenvolvimento humano ao longo do tempo, destaca-se uma transformação nas relações humanas no trabalho e na formação dualística do ensino e a formação para o mercado de trabalho.

Palavras-chave: Trabalho. Formação Humana. Educação. Gestão de Pessoas. Globalização.

\begin{abstract}
The present study aims to analyze the relationships between human education, education and work and understand how to train human development over time, highlighting fundamentals, controversies and challenges. Among the authors researched for the conceptual constitution of the work, we highlight Ramos (2002), Saviani (2007), Felizardo (2010) and Santagada (2007). It is used as methodology to the descriptive research, having as collection of data the bibliographic survey. Therefore that it is relevant to understand how the process of human development occurs over time, there is a transformation in human relations at work and in the dual training of education and training for the labor market.
\end{abstract}

Keywords: Work. Human formation. Education. People management. Globalization.

Resumen: El presente estudio tiene como objetivo el análisis de las relaciones entre formación humana, educación y trabajo y comprender como formador de desarrollo humano a lo largo del tiempo, destacándose fundamentos, controversias y desafíos. Entre los autores investigados para la constitución conceptual del trabajo, se destacaron Ramos (2002), Saviani (2007), Felizardo (2010) y Santagada (2007). Se utiliza como metodología a la investigación descriptiva, teniendo como recolección de datos el levantamiento bibliográfico. Concluye que es relevante la comprensión de cómo ocurre el proceso formador de desarrollo humano a lo largo del tiempo, se destaca una transformación en las relaciones humanas en el trabajo y en la formación dualística de la enseñanza y la formación para el mercado de trabajo.

Palabras clave: Trabajo. Formación Humana. Educación. Gestión de personas. La globalización.

${ }^{1}$ Faculdade de Gestão Woli (FGW), Araxá, MG. E-mail: $\underline{\text { cazarotti@edu.uniube.br }}$ 


\section{INTRODUÇÃO}

O presente estudo delimita-se a apresentar reflexões sobre o conceito das relações entre formação humana, educação e trabalho, sobre a ótica da globalização e seus efeitos na sociedade, principalmente no Trabalho e na Educação.

O objetivo geral é a análise das relações entre formação humana, educação e trabalho e compreender como formador de desenvolvimento humano ao longo do tempo, destacando-se fundamentos, controvérsias e desafios. Os objetivos específicos remetem a: identificar fundamentos históricos, culturais, sociais, políticos e filosóficos para a pesquisa proposta; discutir os desafios sociais, culturais, científicos e pedagógicos para o desenvolvimento humano.

Esta pesquisa justifica-se pela relevância do estudo na necessidade de responder como a formação humana pode ser limitada, de acordo com Zeichner (1998) sendo considerada por alguns estudiosos como apenas uma formação especializada, no entanto é desenvolvida além do conhecimento acadêmico. Além disso, os resultados poderão contribuir para ampliar o debate sobre o tema, além de servir como fonte de consulta para leitores que se interessam sobre as questões relacionadas à gestão e formação de pessoas.

\section{MÉTODOS}

A metodologia deste trabalho é a pesquisa descritiva, tendo como coleta de dados o levantamento bibliográfico, assumindo uma abordagem qualitativa. A pesquisa bibliográfica teve como aporte autores como Lima e Mioto (2007), enquanto a análise documental pautou-se em Cellard (2008). No processo investigativo decorrente, envolvemos os seguintes procedimentos: mapeamento do estado do conhecimento e revisão da literatura; destaque de unidades significativas referentes a cada uma das perguntas de fundo de modo a evidenciar os aspectos relevantes do fenômeno estudado; preenchimento de quadros de análise dos dados e/ou informações contidos no material selecionado; leitura interpretativa, procurando relacionar as ideias expressas nos textos com o problema para o qual se buscou resposta; registro de contribuições dos textos para o estudo proposto, com reflexões, questionamentos e encaminhamentos suscitados pelas leituras, bem como na indicação de como poderiam ser utilizados na elaboração do texto final.

\section{RESULTADOS \& DISCUSSÃO}

\section{As relações entre formação humana, educação e trabalho}

Podemos, ainda, de acordo com Daniels \& Daniels (1996) dizer que o Fundo Monetário Internacional (FMI) interferi na globalização e se constituiu um motor de mudanças na educação, a partir do fim do século $\mathrm{XX}$, e contribuiu para o incremento à criação de uma educação profissional, voltada ao mercado de trabalho.

Também nos anos 1980, para Schrader (2002) citado por Santagada (2007), "[...] muitos países industrializados deslocaram o foco de atenção política do social para o econômico e para uma orientação conservadora [...]', baseados numa orientação neoliberalista, aumentando a distância entre os países. Segundo Relatório do Desenvolvimento Humano do Programa das Nações Unidas para o Desenvolvimento (PNUD/ONU) - Relatório de Desenvolvimento Humano 2014 "Sustentando o Progresso Humano: Redução da Vulnerabilidade e Construção da Resiliência" foi lançado em 24 de julho de 2014, em Tóquio, no Japão. Disponível na UNDESA 2011 - havia três bilhões de pobres no planeta, enquanto aumentava a concentração de renda (SCHRADER, 2002, p. 18 apud SANTAGADA, 2007:121). Segundo Médici (2006), "no Brasil, a Constituição Cidadã de 1988 privilegiava as políticas sociais, porém, a inflação de três dígitos, a crise nas finanças públicas e os direitos constitucionais suprimidos pela ditadura configuravam conflitos a serem enfrentados pela nova ordem social e política". 
Segundo Saviani (2007), a sinergia entre trabalho e educação surge da relação de identidade: o homem aprendeu a garantir a subsistência no ato de produzi-la, ou seja, aprendeu a trabalhar trabalhando, transformando o meio ambiente e inter-relacionando-se.

Nas sociedades primitivas, o homem apropriava-se "[...] coletivamente dos meios de produção da existência e nesse processo educavam-se e educavam as novas gerações. Prevalecia, aí, o modo de produção comunal, também chamado de "comunismo primitivo". Não havia a divisão em classes. Tudo era feito em comum" (SAVIANI, 2007:154). No processo de produzir a existência comum, educavam-se simultaneamente.

"Na nascente civilização do Egito, já existia divisão entre ensino e trabalho, ensino, tanto religioso como técnico, era restrito a poucos, como os sacerdotes, que submetiam os alunos a práticas de iniciação na Mesopotâmia, o ensino era familiar, repassado de geração em geração, de pais para filhos, transmitindo, assim, os saberes. De início, predominava a educação doméstica, em que os saberes, crenças e habilidades eram transmitidos de pai para filho. Após 1240 a.C., quando os assírios conquistaram a Babilônia, foram criadas escolas públicas" (MARX, 1983).

Conforme Teixeira (1999), para Platão, a educação deveria ser repassada conforme as necessidades e diferenças do meio social que, para ele, existiam entre as pessoas, para que cada indivíduo pudesse ocupar seus cargos na sociedade, o que acontecia por seguidas seleções.

Saviani (2007) explica que o processo de produção, ao longo dos anos, possibilita-se separar o ensino da produção. Essa separação espelha o afastamento da manufatura e do trabalho intelectual. Mas, após a divisão, observa-se que a relação trabalho-ensino assume uma dupla identidade:

"De um lado, continuamos a ter, no caso do trabalho manual, uma educação que se realizava concomitantemente ao próprio processo de trabalho. De outro lado, passamos a ter a educação de tipo escolar destinada à educação para o trabalho intelectual" (SAVIANI, 2007:157).

Com a Revolução Industrial, a indústria passa a dominar a produção, materializam-se as funções intelectuais no processo produtivo e a escola passa a dar a orientação intelectual para a sociedade, generalizando a escola básica. "Portanto, à Revolução Industrial correspondeu uma Revolução Educacional: aquela colocou a máquina no centro do processo produtivo; esta erigiu a escola em forma principal e dominante de educação" (SAVIANI, 2007:157).

Na produção, o capitalista apropria-se do saber historicamente acumulado pelo trabalhador, "[...] de suas ferramentas de trabalho e da decisão sobre o que, como, quando e para que produzir" (FELIZARDO, 2010:5). O trabalhador torna-se uma etapa da produção.

A evolução tecnológica permitiu controlar o processo produtivo e aumentar a produtividade. Por sua vez, o capital tratou de educar e orientar a mão de obra, garantindo a posse do saber do trabalhador.

De acordo com Braverman (1987) o capitalismo, em busca de aumento de produtividade, converge-se para o desenvolvimento da tecnologia industrial (século XVIII), o que permite romper as fronteiras entre as nações, em busca de mercados e mão de obra mais atrativos. Assim, para que possa inserir-se no mercado de trabalho, o trabalhador precisa dominar qualificações cada vez mais complexas e variadas, além de ter de saber usar tecnologias indispensáveis da vida moderna, como a informática (FELIZARDO, 2010:37).

Em busca de sobrevivência, o homem viu-se obrigado a transformar o ambiente natural e a si mesmo. Como diz Saviani (2007), o homem, a fim de garantir a subsistência, aprendeu a trabalhar realizando atividades laborais, o qual se transforma o meio ambiente, que faz uma interligação com seus pares, reeducando, e educando a geração seguinte, até que, com a sociedade de classes (escravista/feudal) separaram-se educação e trabalho, a manufatura do trabalho intelectual. Para Oliveira (2004), no entanto, 
na manufatura, permanecia a necessidade de educar-se o trabalhador no próprio processo de trabalho, essa é a natureza do ensino técnico que, com variações, perdura até hoje, com a globalização, capital força o desenvolvimento da tecnologia industrial, o que passa a exigir um trabalhador qualificado.

No Brasil, desde a criação de liceus de artes e ofícios, em São Paulo e no Rio de Janeiro, buscava-se disseminar, entre os operários, a instrução artística e técnica, das artes e dos ofícios industriais. Na época contemporânea, o panorama do ensino profissionalizante é complexo, dividindo-se em: 1) educação inicial, que busca qualificar quem procura emprego ou requalificar quem está empregado, por meio de cursos rápidos oferecidos por Organizações Não Governamentais, instituições públicas, associações, sindicatos; 2) formação tecnológica, visando à profissionalização de nível superior; 3) formação técnica, destinada a formandos do Ensino Fundamental que desejam a profissionalização no Nível Médio (BRASIL, MEC/ Plano Nacional de Educação-PNE - 2014-2024, 2014).

Oliveira e Carneiro (2012:16) ${ }^{2}$ esse contexto está conformado, hoje, por uma série de leis, decretos e resoluções que têm sido colocados em prática pelas três instâncias de governo e pela iniciativa privada ou organizações classistas e sem fins lucrativos, isso permitiu que, entre os anos de 2001 e 2010, o total de matrículas na educação técnica profissional de Nível Médio crescesse 129,7\% (cento e vinte e nove vírgula sete) por cento.

No Brasil, conforme o "Relatório Educação para Todos no Brasil 2000-2015", só o Pronatec cresceu 278,1\% (duzentos e setenta e oito vírgula um) por cento, em três anos (2011-2014), com mais de sete milhões de alunos (BRASIL. Relatório educação para todos no Brasil 2000-2015, MEC. 2014).

Além das bem-sucedidas políticas de inclusão e diversidade de então, a meta que avizinha é a universalização, sendo o foco da política educacional de equilibrar metas quantitativas e qualitativas a fim de reduzir as desigualdades.

No ano de 2015, em visita ao presidente Barack Obama, a ex-presidente Dilma Rousseff aproveitou para discutir a experiência americana de ensino profissionalizante com as community colleges, ou seja, com as faculdades que oferecem, naquele país, cursos superiores de dois anos de duração que dão diploma de técnico ou servem como períodos iniciais para completar a formação em uma universidade, já observando fatores da globalização que estão interferindo no processo educacional brasileiro (Department of State, The Washington Post, 2015).

O maior desafio da educação profissional está em atender às necessidades e às exigências de empresas que estão, cada vez mais, buscando ampliar sua qualidade em relação ao conhecimento e ao capital intelectual, o que muitas vezes não é acompanhado pela educação profissional.

Considerando as constantes mudanças que rondam as exigências do mercado de trabalho e o crescimento do ensino superior no Brasil, analisa-se a importância em assegurar a valorização da diversidade na era rápida da informação, visto que as transformações sociais, políticas, econômicas e culturais aumentam a cada dia (SILVA, 2008:16).

É notório que essas transformações conseguem influenciar a demanda educacional. Antigamente, as mudanças na sociedade demoravam um longo tempo para ocorrer. Nos dias de hoje, as mesmas ocorrem de maneira mais rápida e gradativa. Assim:

\footnotetext{
2 Oliveira e Carneiro (2012, p. 16) elucidam que "[...] no governo Lula houve um fortalecimento da Rede Federal de Educação, com ampliação da oferta de vagas, qualificação permanente dos servidores técnicos, administrativos e docentes, além da qualidade e investimento no ensino, pesquisa e extensão. Todas essas iniciativas contribuíram de forma positiva para a superação do modelo neoliberal na educação profissional". Atualmente, vivemos um momento oposto quanto à expansão de vagas, em decorrência da ideologia partidária que ocupa o poder.
} 
"À universidade resta o compromisso de gerar o saber, o qual está interligado à verdade, justiça e igualdade. Entretanto a quantidade de ofertas no ensino superior não reflete, necessariamente, qualidade. Observa-se que os formandos deixam suas cadeiras e partem rumo à vida profissional, carentes de o verdadeiro saber. Tal fato se deve ao distanciamento entre $o$ conteúdo das disciplinas - constante nos currículos - e a velocidade das transformações nos variados campos do conhecimento científico e tecnológico. O ingresso ao mercado de trabalho torna-se extremamente penoso à medida que o profissional carece de uma boa formação universitária" (SILVA, 2008:48).

Nesse sentido, o aumento da qualificação dos profissionais docentes, juntamente com 0 desenvolvimento de novas metodologias pedagógicas, faz-se totalmente necessário, devendo estar ambas voltadas para a interação entre alunos e professores, contribuindo para a humanização do ensino superior.

Com isso, as transformações econômicas são responsáveis por influenciar as regras e padrões praticados pelo ensino. Os aspectos atuais da educação envolvem tendências relacionadas ao crescimento futuro dessa área, refletindo, significativamente, na promoção do desenvolvimento social e cultural, transformando as instituições de ensino superior em organizações incentivadoras do conhecimento.

Atualmente, o ensino superior, no Brasil, mantém ainda posturas associadas aos modelos mais antigos de educação, estabelecidas pelos modelos europeus; porém, estes modelos sofreram mudanças significativas, em que as propostas pedagógicas se tornaram mais exigentes e complexas, visando ao aumento da qualidade do ensino superior no país (PIMENTA; ANASTASIOU, 2002:45).

É por meio da valorização dos aspectos econômicos que ocorre a comercialização do ensino, predominando a busca por ações que visem ao crescimento do ensino superior por meio de critérios utilitaristas. Nessa direção, a educação passará a apresentar o objetivo de atender aos interesses de determinada parcela da sociedade. Assim, o ambiente de educação superior não possui apenas a missão de educar o cidadão, mas também de contribuir com o desenvolvimento econômico do país.

Em relação ao papel público no desenvolvimento do ensino superior, Schwartzman (2007) considera que as políticas públicas não devem se preocupar apenas com o financiamento e com as regulamentações de todo o sistema educacional superior. Cabe ao governo, também, desenvolver estratégias e ações que visem à estimulação da pesquisa, ao aumento da qualidade do ensino, à valorização da diversificação regional. Através destes objetivos é possível estimular o desenvolvimento de outras áreas estratégicas, promovendo a equidade e proporcionando a toda a população brasileira melhores condições de infraestrutura, assegurando normas consistentes para que a educação superior possa ser efetivada.

Observa-se que a educação superior possui uma organização social, cujo objetivo é disponibilizar oportunidades de crescimento intelectual e científico para toda a população, cabendo à mesma adotar uma postura de acordo com normas e valores determinados pela sociedade na qual se insere. Dessa maneira, é caracterizada pelo importante papel estável e durável em sua comunidade. De modo geral, as Instituições de Ensino Superior devem estar baseadas em um ideal integrador entre a qualificação dos alunos e o incentivo ao desenvolvimento da nação.

Schwartzman (2007), ao analisar o campo de forças voltadas para essas organizações, constatou a existência de ações responsáveis por impulsionar transformações relevantes em seu ambiente, dentre as principais:

- a criação da nova Lei de Diretrizes e Bases da Educação Superior, responsável por estabelecer critérios que visem ao credenciamento e ao descredenciamento das IES; - a realização do Provão como um novo método de avaliação de desempenho dos alunos nos cursos ofertados; - a avaliação da própria instituição, permitindo assegurar o crescimento do ensino juntamente com a melhoria da qualificação dos professores e, consequentemente, o aumento da qualidade das propostas pedagógicas. 
O entendimento das transformações das Instituições de Ensino Superior demonstra novos rumos para o crescimento e, em consequência, a redução dos obstáculos impostos. Daí pode-se incorporar aos cursos maior domínio das exigências do mercado profissional, sendo possível inclusive, identificar as melhores ações a serem utilizadas, para aumentar a flexibilidade da educação superior (SANTOS, 2004).

Com base nesta ideia, Santos (2004) afirma que o termo "ensino superior" sugere uma educação com excelência que se encontra de acordo com os critérios quantitativos e qualitativos da sociedade, sendo considerado um modelo para as outras formas de ensino, havendo a denotação de superioridade. Observase que esta expressão, assim como seus significados simbólicos que a mesma apresenta, fortaleceram-se "[...] no seio da sociedade de tal maneira que há uma espécie de senso comum em torno do termo, que garante uma mesma expectativa para quem ingressa ou participa, de forma direta ou indireta, desta etapa da formação acadêmica ou escolar" (SANTOS, 2004:1).

A sociedade, em geral, espera que esse ensino seja efetivado com base em suas expectativas, desejando que a educação superior seja decisiva para o ingresso dos jovens no mercado de trabalho, havendo o encaminhamento à realização profissional. Muitos pais esperam que seus filhos ingressem em uma faculdade e adquiram o conhecimento necessário para garantirem sua autonomia financeira futuramente. Por sua vez, os estudantes desejam obter uma carreira de sucesso e manter um cargo de destaque no segmento que escolheram (SANTOS, 2004:22).

Assim sendo, o ensino, a Educação, deve assegurar que seus alunos tenham acesso a conhecimentos específicos dos cursos escolhidos, de modo que possam empregar essas informações nos ambientes profissionais em que atuarão.

\section{CONSIDERAÇÕES FINAIS}

Assim, analisando as relações entre formação humana, educação e trabalho e compreensão como formador de desenvolvimento humano ao longo do tempo, destaca-se,, uma transformação nas relações humanas no trabalho e na formação dualística do ensino e formação para o mercado de trabalho.

Em relação a esses critérios de pesquisa, frente à complexidade dos fenômenos sociais e os processos e estruturas impostos sobre a produção e gestão da vida cotidiana em toda a sociedade, o objetivo que predomina no ensino, como depreendemos do estudo realizado, sobretudo no que se refere a formação humana, é a formação do profissional para atuar no mercado de trabalho.

Num primeiro momento, esse processo de formação parece contribuir para a formação integral do cidadão, conciliando o ingresso no mercado de trabalho, o aumento da renda e a formação em nível superior. Mas um olhar mais atento e uma leitura de alguns autores como Felizardo (2010), Ramos (2002), Saviani (2007), e Santagada (2007) entre outros citados no presente estudo, permite observar que prevalece no Brasil a formação baseada no modelo capitalista, muito parecida com aquela do período colonial e escravagista.

No entanto, essa é uma generalização que não contempla propostas acadêmicas opostas, que enfatizam a formação ética, político-crítica e transformadora. Há uma evolução, nesse sentido, na educação e no trabalho, sobretudo na formação humana-profissional.

Em resposta ao problema de pesquisa apresentado na introdução deste estudo (identificar fundamentos históricos, culturais, sociais, políticos e filosóficos para a pesquisa proposta), concluímos que a melhoria da qualidade do ensino passa pela inserção de conteúdos científicos voltados para a reflexão, pesquisa e formação da conduta profissional dos indivíduos, ou seja, uma formação profissional também científica e não somente técnica escravagista. 
Para melhor aprofundamento neste contexto de formação e pesquisa sobre relações de trabalho e a educação, sugere-se uma pesquisa na qual destacará uma transformação nas relações humanas no trabalho com uma visão e olhar sobre o mercado de trabalho, busca-se assim uma visão sistêmica sobre o problema e não somente educacional.

\section{REFERÊNCIA}

1. BRASIL. Presidência da República. Casa Civil. Subchefia para Assuntos Jurídicos. Lei no 13.005, de 25 de junho de 2014 . Plano Nacional de Educação-PNE - 2014-2024.

2. BRASIL. Relatório educação para todos no Brasil 2000-2015 (versão preliminar). Ministério da Educação e Cultura. junho, 2014.

3. BRAVERMAN, H. Trabalho e capital monopolista: a degradação do trabalho no século XX. 3.ed. Rio de Janeiro: LTC, 1987.

4. BRUM, A. J. Desenvolvimento Econômico Brasileiro. Petrópolis: Vozes, 2002.

5. CAZAROTTI, M. L. B. A Globalização como motor de mudanças na educação a partir do fim do século XX: cursos tecnológicos. Trabalho inscrito para o GT Comunicação e Educação, do VII Encontro de Pesquisa em Comunicação ENPECOM. Disponível em: < https://eventos.ufpr.br/enpecom/enpecom2015/paper/download/132/42>. Acessado em 30/07/2018.

6. CELLARD, A. A análise documental. In: POUPART, Jean et al. A pesquisa qualitativa: enfoques epistemológicos e metodológicos. Petrópolis: Vozes, 2008 (Coleção Sociologia).

7. Daniels, J. L.; Daniels, e. Visão Global: Criando novos modelos para as empresas do futuro. São Paulo: Makron Books, 1996.

8. DUMÉNIL, G.; LÉVY, D. Neoliberal dynamics - Revist: Imperial dynamics. Paris. 2003.

9. FELIZARDO, J. M. Capitalismo, organização do trabalho e tecnologia da produção e seus impactos na qualificação da força de trabalho. 2010. Revista Labor, n. 3, v. 1, 2010.

10. FIORI, J. L. Ajustes e milagres latino-americanos. In: _. Os Moedeiros Falsos: pp. 65-78. Petrópolis: Vozes, 1997.

11. HOBSBAWM, E. Era dos extremos - o breve século XX. Ed. Companhia das letras. 1995.

12. IBGE. Pesquisa Nacional por Amostra de Domicílios (PNAD) 1999/1979. Disponível em: <http://www.ibge.gov.br>. Acesso em: 2018.

13. LIMA, T. C. S.; MIOTO, R. C. T. Procedimentos metodológicos na construção do conhecimento científico: a pesquisa bibliográfica. Revista Katalysis, v. 10, p. 35-45, 2007.

14. MARQUES, A. A. A pedagogia tecnicista: um breve panorama. Revista Eletrônica do Curso de Pedagogia do Campus Jataí UFG, v. 1, ํㅜ 12, 2012.

15. MARX, K. "Prefácio". MARX, K. Contribuição à Crítica da Economia Política. São Paulo : Martins Pontes, (2a. ed.). 1983.

16. MÉDICI, A. Welfare State no Brasil. Curso de Formação de Formadores para Gestão de Políticas Públicas no Sistema Público de Emprego e Renda. 11 maio 2006.

17. LIN, J. Y. New Structural Economics: A Framework for Rethinking Development. The World Bank Research Observer, vol. 26, $\mathrm{n}^{\circ}$ 2, pp. 193-221. 2011.

18. OLIVEIRA, J. F, A. C. de; CARNEIRO,M. E. F. As políticas neoliberais para a educação profissional: analisando o governo Fernando Henrique Cardoso e Luís Inácio Lula da Silva. IV SENEPT - Seminário Nacional de Educação Profissional e Tecnológica15 -16 e setembro no CEFET/ Belo Horizonte MG. 2012.

19. OLIVEIRA, D. A. A reestruturação do trabalho docente: precarização e flexibilização. Educação \& Sociedade, Campinas, v.25, n.89, p.1127-1144, set./dez. 2004.

20. ORGANIZAÇÃO DOS ESTADOS IBERO-AMERICANOS. Sistema Educativo Nacional de Brasil. 2010. Disponível em: <http://www.oei.es/quipu/brasil/contexto.pdf>. Acesso em: junho de 2018.

21. PIMENTA, S. G.; ANASTASIOU, L. G. C. Docência no ensino superior. São Paulo: Cortez, 2002. v. 1.

22. RAMOS, J. M. R. Dimensões da globalização: comunicações, economia, política e ética. Revista de Economia \& Relações

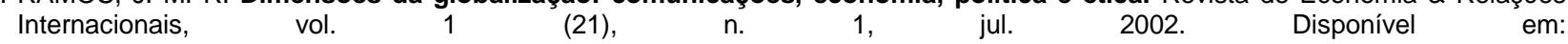
<http://www.faap.br/revista_faap/rel_internacionais/rel_01/dimensoes.htm>. Acesso em: junho de 2018.

23. SANTAGADA, S. Indicadores sociais: uma primeira abordagem social e histórica. Pensamento Plural, Pelotas, n. 01, p.113142, jul/dez/2007. Disponível em http://pensamentoplural.ufpel.edu.br/edicoes/01/06.pdf. Acesso em: junho de 2018.

24. SANTOS, M. H. Construindo a competência. São Paulo: Olho d'Água, 2004.

25. SANTOS, N. F. A formação inicial de professores de física em centros federais de educação tecnológica: contribuições e críticas. Rio de Janeiro. RJ. 2004. Dissertação (Mestrado em Educação) - Centro de Educação e Humanidades, Universidade do Estado do Rio de Janeiro, 2004. Disponível em: <http://www.curriculo-uerj.pro.br/imagens/pdfteses/a_formacao_44.pdf> . Acesso em: junho de 2018.

26. SAVIANI, D. Trabalho e educação: fundamentos ontológicos e históricos. Revista Brasileira de Educação, v. 12, n. 34 jan./abr. 2007. Faculdade de Educação, Universidade Estadual de Campinas, 2007.

27. SCHWARTZMAN, S. Por uma nova política de educação superior para o Brasil. 2007. Disponível em: < http://www.schwartzman.org.br/simon/poledsup.pdf>. Acesso em: junho de 2018.

28. SILVA, D. A. O papel do professor no processo ensino- aprendizagem face das contínuas e rápidas mudanças advindas no decorrer do séc. XXI. 2008. Disponível em: http://www.artigonal.com/ensino-superior-artigos/o -papel-do-professor-no- processoenisno-aprendizagem-face-das-continuas-e-rapidas-mudanças- advindas-no-decorrer-do-sec-xxi-385590.html. Acesso em: junho de 2018.

29. TEIXEIRA, E.; F. B. A educação do homem segundo Platão. São Paulo: Paulus,1999

30. THE WASHINGTON POST. Corn Power: Sen. Grassley snuffs out dissent on ethanol subsidies - Editorial. 2015.

31. KUZNETS, S. "Economic Growth and Income Inequality". The American Economic Review, vol. 45, n 1, 1955.

32. ZEICHNER, K. M. Para além da divisão entre professor-pesquisador e pesquisador acadêmico In: GERALDI, Corinta M.; FIORENTINI, Dario \& PEREIRA, Elisabete M. (orgs.) Cartografia do trabalho docente:professor(a)-pesquisador(a). Campinas, Mercado de Letras?ABL, 1998. pp. 207-236. 